\title{
Optimized Extraction of Polysaccharides from Grateloupia livida (Harv.) Yamada and Biological Activities
}

\section{Danyan Ye ${ }^{1}$, Zebin Jiang ${ }^{2}$, Fuchun Zheng ${ }^{2}$, Hongmei Wang ${ }^{1}$, Yanmei Zhang ${ }^{1}$, Fenfei Gao ${ }^{1}$, Peihong Chen ${ }^{1}$, Yicun Chen ${ }^{1,3, *}$ and Ganggang Shi ${ }^{1,3,4, *}$}

1 Department of Pharmacology, Shantou University Medical College, Shantou 515041, China; E-Mails: 15917907394@163.com (D.Y.); junebulu@163.com (H.W.); ymzhang@stu.edu.cn (Y.Z.); ffgao@stu.edu.cn (F.G.); m13411961378@163.com (P.C.)

2 Department of Pharmacy, First Affiliated Hospital, Shantou University Medical College, Shantou 515041, China; E-Mails: jzbwood@126.com (Z.J.); zhengfuchunsh@163.com (F.Z.)

3 Traditional Chinese Medicine Laboratory, Shantou University Medical College, Shantou 515041, China

4 Department of Cardiovascular Diseases, First Affiliated Hospital, Shantou University Medical College, Shantou 515041, China

* Authors to whom correspondence should be addressed; E-Mails: chenyicun@yeah.net (Y.C.); ggshi@stu.edu.cn (G.S.); Tel.: +86-754-8890-0430 (Y.C.); +86-754-8890-0301 (G.S.); Fax: +86-754-8890-0432 (Y.C.); +86-754-8855-7562 (G.S.).

Academic Editor: Derek J. McPhee

Received: 17 August 2015 / Accepted: 10 September 2015 / Published: 16 September 2015

\begin{abstract}
Polysaccharides from Grateloupia livida (Harv.) Yamada (GL) were extracted by a heating circumfluence method. Single-factor experiments were performed for the three parameters: extraction time $\left(\mathrm{X}_{1}\right)$, extraction temperature $\left(\mathrm{X}_{2}\right)$ and the ratio of water to raw material $\left(\mathrm{X}_{3}\right)$ and their test range. From preliminary experimental results, one type of the response surface methodology, the Box-Behnken design was applied for the optimizing polysaccharide extraction conditions. The experimental data obtained were fitted to a second-order polynomial equation. The optimal conditions were extraction time $5 \mathrm{~h}$, extraction temperature $100{ }^{\circ} \mathrm{C}$ and ratio of water to raw material $70 \mathrm{~mL} / \mathrm{g}$. Under these conditions, the experimental yield was $39.22 \% \pm 0.09 \%$, which well matched the predicted value $(39.25 \%)$, with 0.9774 coefficient of determination $\left(R^{2}\right)$. GL polysaccharides had scavenging activities for DPPH and hydroxyl radicals in vitro. The scavenging rates for both radicals peaked at $20 \mathrm{mg} / \mathrm{mL}$ GL concentration. However, the positive standard, VC (ascorbic acid), possessed
\end{abstract}


stronger antioxidant activities than GL polysaccharides. Furthermore, the anticancer activity of GL polysaccharides on HepG2 cell proliferation increased dose- and time-dependently, but the positive standard, 5-fluorouracil (5-fu) showed more significant anticancer activity in this study. Overall, GL polysaccharides may have potential applications in the medical and food industries.

Keywords: Grateloupia livida (Harv.) Yamada; polysaccharide extraction; Box-Behnken design; antioxidant and anti-cancer activity

\section{Introduction}

Marine algae are classified by their colors, mainly red, green, and brown algae. The red algae have a special red color because of the algae pigments and accessory pigments, and different living water layers lead to different ratios of accessory pigments, so different species of red algae have different colors, ranging from yellowish-red to purplish-red [1]. Worldwide, red algae represent 4000 species in 500 genera: the most common species are Gloiopeltis tenax (Turn.) J. Ag, Gracilaria verrucosa (Huds.) Papentf, Grateloupia filicina. C. Ag, Grateloupia livida (Harv.) Yamada and Grateloupia turuturu [2]. In recent years, most research has involved the Grateloupia family, finding that extracts from the Grateloupia family have wide biological effects such as antiangiogenic [3], antioxidant [4], antiviral [5], anti-allergic [6], and anticancer activities [7].

G. livida (Harv.) Yamada (GL), a red algae belonging to Rhodophyta, Rhodophyceae, Gigartinales, Halymeniaceae, is mainly distributed in the coastal warm temperate zone [8]. It is an edible and medicinal seaweed, usually used for treating sore throat, stomachache, ascariasis and seaworm infections and dysentery [9]. Red algae (Rhodophyta) are characterized by their content of non-fibrillar and sulfated polysaccharides such as carrageenans, agars and complex sulfated galactans, which are classified by their structural features $[10,11]$. Sulfated polysaccharides are acidic polysaccharides containing sulfate groups of natural and semi-synthetic anionic compounds [12]. GL polysaccharides are mainly composed of galactose linked with sulfate ester, and the exquisite structure including the replacement mode of sulfate ester is related to its bioactivities [13]. Many studies were performed to demonstrate that polysaccharides from the Grateloupia family had outstanding antioxidant and anticancer activities. Extracts from seaweed were found to have a strong antioxidant effect $[14,15]$ and Grateloupia polysaccharides could inhibit ECA-109 [16] and U87 cell proliferation [17].

To make the best use of effective polysaccharides and enhance their extraction yield, attention has been paid to the extraction methods of polysaccharides from plants and algae. Extraction methods developed include the ultrasound-, microwave- and enzyme-assisted extraction methods [18]. Considering its simple and economical conditions, hot water extraction [19] has been widely used as the classical method for polysaccharides extraction. However, hot water extraction involves a long time and high temperature, so the extraction method needs to be optimized.

Response surface methodology (RSM) is an effective statistical technique for optimizing complex processes. The main advantage is to reduce the experimental trials needed to evaluate multiple factors and their interactions. The Box-Behnken design (BBD), one type of RSM, is more efficient and easier to 
arrange and interpret results for than other methods [20]. It is widely used in optimizing extraction process variables, such as polysaccharides, protein, anthocyanins and phenolic compounds [21].

According to our preliminary research, we separated the ethanol extract, petroleum ether, ethyl acetate, $n$-butyl alcohol and aqueous fractions from GL and discovered antioxidant, antibacterial and antischistosomal bioactivities [8]. In this experiment, we studied the extraction of aqueous fractions, or polysaccharides. The extraction conditions of polysaccharides were optimized to increase the extraction yield. Furthermore, we evaluated the scavenging and anticancer activities of GL polysaccharides with the aim of exploitation for medicines and foods.

\section{Results and Discussion}

\subsection{Single-Factor Experimental Analysis of G. livida (Harv.) Yamada (GL) Polysaccharide Extraction}

The extraction time, extraction temperature and ratio of water to raw material were studied and the results of single-factor experiments are shown in Figure 1. The three factors were effective for the yield of GL polysaccharides. The most suitable conditions were chosen for use in the BBD design.

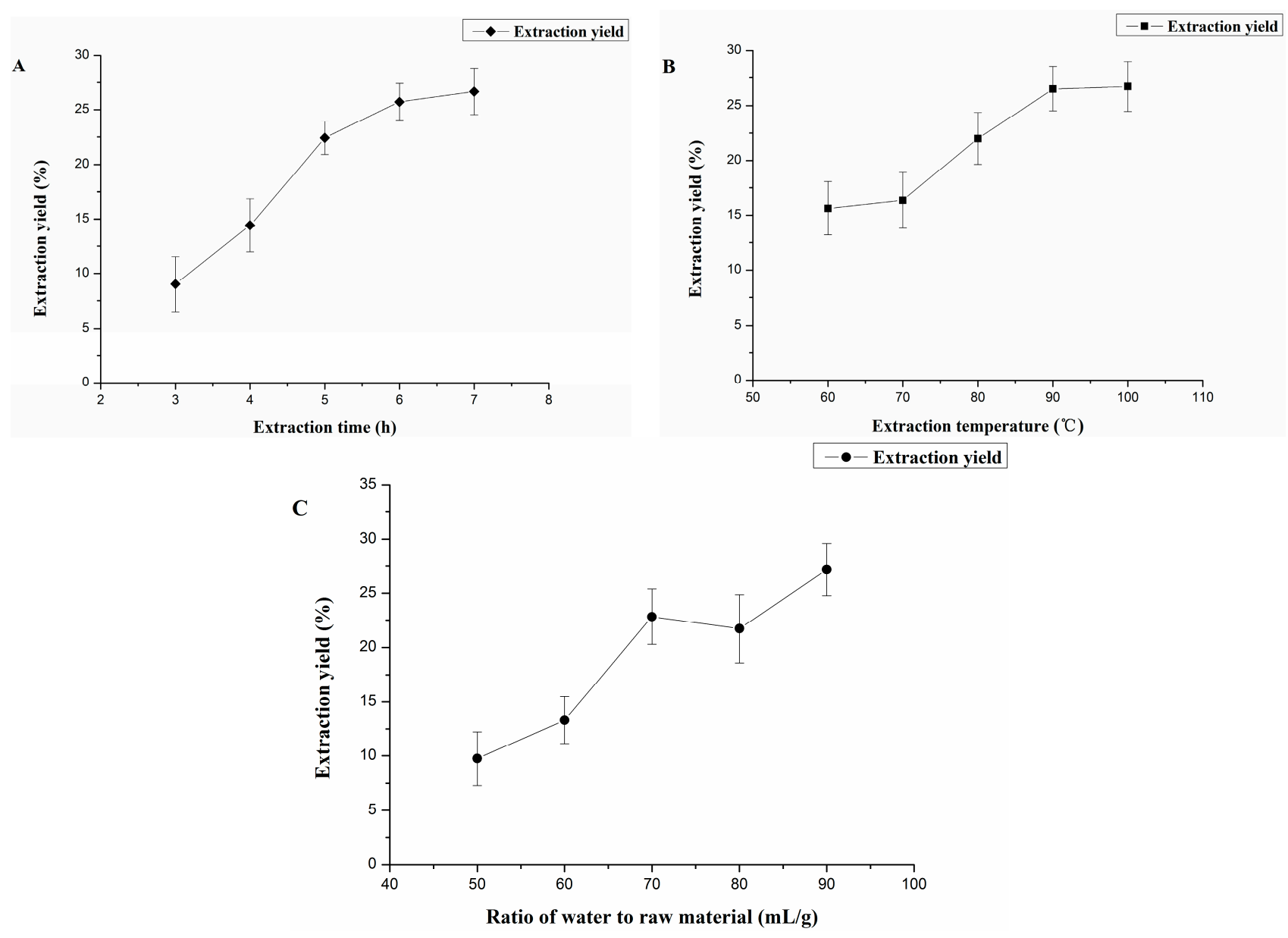

Figure 1. Effect of extraction time (A); extraction temperature (B); and ratio of water to raw material (C) on extraction yield of G. livida (Harv.) Yamada (GL) polysaccharides. 


\subsubsection{Effect of Extraction Time on Extraction Yield of GL Polysaccharides}

The effect of extraction time on the yield of GL polysaccharides was investigated with extraction time 3 to $7 \mathrm{~h}$ (Figure 1A), with other extraction parameters fixed, such as an extraction temperature of $90{ }^{\circ} \mathrm{C}$ and ratio of water to raw material of $70 \mathrm{~mL} / \mathrm{g}$. The extraction yield of GL polysaccharides significantly increased from $9.02 \%$ to $22.42 \%$ with extraction time varying from $3 \mathrm{~h}$ to $5 \mathrm{~h}$; it began to plateau with proceeding extraction. The polysaccharides need much time to swell so that they can be released and diffused into water [22]. However, extended extraction time may lead to the degradation of the polysaccharides [23]. Therefore, an extraction time ranging from $4 \mathrm{~h}$ to $6 \mathrm{~h}$ is the best for polysaccharide extraction.

\subsubsection{Effect of Extraction Temperature on Extraction Yield of GL Polysaccharides}

The extraction yield of GL polysaccharides affected by extraction temperature is in Figure $1 \mathrm{~B}$. The extraction process was performed with temperatures from $60{ }^{\circ} \mathrm{C}$ to $100{ }^{\circ} \mathrm{C}$, with the other extraction variables such as ratio of water to raw material and extraction time fixed at $70 \mathrm{~mL} / \mathrm{g}$ and $5 \mathrm{~h}$, respectively. The extraction yield of GL polysaccharides increased with increasing extraction temperature from $60{ }^{\circ} \mathrm{C}$ to $80{ }^{\circ} \mathrm{C}$, then peaked at $26.73 \% \pm 2.25 \%$ at $100{ }^{\circ} \mathrm{C}$. With increasing extraction temperature, the polysaccharide diffusion coefficient increases accordingly, for enhanced solubility of polysaccharides in the extracting solvent [24]. We selected temperatures from $80^{\circ} \mathrm{C}$ to $100^{\circ} \mathrm{C}$ as the appropriate extraction temperature.

\subsubsection{Effect of Ratio of Water to Raw Material on Extraction Yield of GL Polysaccharides}

Different ratios of water to raw material have an effect on extraction yield (Figure 1C). In this study, we used ratios of water to raw material from $50 \mathrm{~mL} / \mathrm{g}$ to $90 \mathrm{~mL} / \mathrm{g}$, with other parameters (extraction time and extraction temperature) fixed at 0 level $\left(5 \mathrm{~h}\right.$ and $\left.90{ }^{\circ} \mathrm{C}\right)$. Extraction yield increased with ratio of water to material from $50 \mathrm{~mL} / \mathrm{g}$ to $70 \mathrm{~mL} / \mathrm{g}$ and decreased before it peaked at $27.19 \% \pm 2.41 \%$ at $90 \mathrm{~mL} / \mathrm{g}$. Under the appropriate condition of ratio of water to raw material, the polysaccharides can swell thoroughly, and more polysaccharide molecules could dissolve in water to improve extraction yield [22]. If ratio of water to raw material is too small, polysaccharides cannot be completely extracted, and if too high, the cost will increase [25]. Thus, we chose ratios of water to material from $60 \mathrm{~mL} / \mathrm{g}$ to $80 \mathrm{~mL} / \mathrm{g}$ as the optimal conditions.

According to the single-factor study, the following conditions could be used for the BBD (Box-Behnken design) experiments: extraction time of 4-6 h, extraction temperature of $80-100{ }^{\circ} \mathrm{C}$ and ratio of water to raw material of $60-80 \mathrm{~mL} / \mathrm{g}$.

\subsection{Box-Behnken Design (BBD) and Analysis}

\subsubsection{Statistical Analysis}

Table 1 shows the BBD with three factors and three levels examined to optimize the mutual effect of three independent variables (extraction time, extraction temperature and ratio of water to material) on extraction yield of GL polysaccharides. The design matrix and experimental and predicted extraction yield of polysaccharides are in Table 2. The yield of GL polysaccharides ranged from $20.3 \%$ to $39.48 \%$ and the maximum yield was with ratio of water to raw material $70 \mathrm{~mL} / \mathrm{g}$ at $100{ }^{\circ} \mathrm{C}$ and $4 \mathrm{~h}$ extraction 
time. On multiple regression analysis, the quadratic polynomial equation for the independent variables and response variable can be expressed as follows:

$$
\begin{aligned}
& Y=37.79+1.27 X_{1}+1.55 X_{2}-1.84 X_{3}-1.22 X_{1}^{2}-0.17 X_{2}^{2}-7.65 X_{3}^{2}-1.84 X_{1} X_{2}+5.10 X_{1} X_{3}+ \\
& 2.73 X_{2} X_{3}
\end{aligned}
$$

Table 1. Factors and levels in the Box-Behnken design used to examine extraction yield of G. livida (Harv.) Yamada (GL) polysaccharides.

\begin{tabular}{cccc}
\hline \multirow{2}{*}{ Independent Symbol Variables } & \multicolumn{3}{c}{ Factor Level } \\
\cline { 2 - 4 } & $\mathbf{- 1}$ & $\mathbf{0}$ & $\mathbf{1}$ \\
\hline Extraction $\mathrm{X}_{1}(\mathrm{~h})$ time & 4 & 5 & 6 \\
Extraction $\mathrm{X}_{2}\left({ }^{\circ} \mathrm{C}\right)$ temperature & 80 & 90 & 100 \\
Ratio of water $\mathrm{X}_{3}(\mathrm{~mL} / \mathrm{g})$ to raw material & 60 & 70 & 80 \\
\hline
\end{tabular}

Table 2. Design and results of Box-Behnken design used to examine extraction yield of G. livida (Harv.) Yamada (GL) polysaccharides.

\begin{tabular}{ccccccc}
\hline \multirow{2}{*}{ Run } & \multicolumn{3}{c}{ Factor Level } & Extraction Yield (\%) & Extraction Yield (\%) & Residue \\
\cline { 2 - 6 } & $\mathbf{X}_{\mathbf{1}}(\mathbf{h})$ & $\mathbf{X}_{\mathbf{2}}\left({ }^{\mathbf{C}} \mathbf{C}\right)$ & $\mathbf{X}_{\mathbf{3}}(\mathbf{m L} \mathbf{g})$ & Experimental & Predicted & -0.68 \\
\hline 1 & 4 & 80 & 70 & 31.07 & 31.75 & 0.95 \\
2 & 4 & 100 & 70 & 39.48 & 38.53 & -0.95 \\
3 & 6 & 80 & 70 & 37.01 & 37.96 & 1.62 \\
4 & 6 & 100 & 70 & 38.06 & 37.44 & 0.53 \\
5 & 5 & 80 & 60 & 33.53 & 33.00 & 1.10 \\
6 & 5 & 80 & 80 & 24.96 & 23.86 & -1.10 \\
7 & 5 & 100 & 60 & 29.53 & 30.63 & -0.53 \\
8 & 5 & 100 & 80 & 31.90 & 32.43 & 0.15 \\
9 & 4 & 90 & 60 & 34.75 & 34.60 & 0.42 \\
10 & 6 & 90 & 60 & 27.35 & 26.93 & -0.42 \\
11 & 4 & 90 & 80 & 20.30 & 20.72 & -1.09 \\
12 & 6 & 90 & 80 & 33.31 & 34.40 & 1.44 \\
13 & 5 & 90 & 70 & 39.23 & 37.79 & -1.27 \\
14 & 5 & 90 & 70 & 36.52 & 37.79 & -0.16 \\
15 & 5 & 90 & 70 & 37.63 & 37.79 &
\end{tabular}

A summary of the ANOVA parameters for the fitted quadratic polynomial model for extraction yield of GL polysaccharides is in Table 3. The $F$-test was used to check the statistical significance of the regression equation and $p$ values to check the significance of each coefficient, which in turn may indicate the pattern of the interactions between the variables [26]. The model $f$-value for the model was 24.01 and the $p$-value was 0.0014 , so the model was significant. The probability that the large $f$-value could occur due to noise was $0.14 \%$. The smaller the $p$-values, the larger the significance of the corresponding coefficient [27]. The linear coefficients $\left(\mathrm{X}_{2}\right.$ and $\left.\mathrm{X}_{3}\right)$, interaction terms $\left(\mathrm{X}_{1} \mathrm{X}_{2}, \mathrm{X}_{1} \mathrm{X}_{3}\right.$ and $\left.\mathrm{X}_{2} \mathrm{X}_{3}\right)$ and quadratic term $\left(\mathrm{X}_{3}^{2}\right)$ were significant $(p<0.05)$ (Table 3$)$. The adequacy of the model could be confirmed by the determination coefficient $\left(R^{2}\right)$ [28]. The determination coefficient $\left(R^{2}=0.9774\right)$ suggested that the model was valid, implying that $97.74 \%$ of the variation could be explained by the fitted model. The adjusted determination coefficient was used to evaluate the correlation between the experimental values 
and predicted values, and the outcome $\left(R_{A d j}^{2}=0.9367\right)$ suggested that the correlation was significant. The $f$-value (6.12) for "the lack of fit" indicated that the "lack of fit" was not significant relative to the pure error $(p>0.05)$. As a general rule, the coefficient of variation $(\mathrm{CV})$ should not be $>10 \%$ [29]. The CV for yield of GL polysaccharides was $4.25 \%$, which indicated a good reliability of the experimental values. Adequate precision measures the signal to noise ratio. Its desired value is $\geq 4$ [30]. The adequate precision value for our model of 15.554 indicated an adequate signal and that the model could be used to navigate the design space.

Table 3. ANOVA of the experimental data.

\begin{tabular}{cccccc}
\hline Source & Sum of Squares & df & Mean Square & $\boldsymbol{f}$-Value & $\boldsymbol{p}>\boldsymbol{f}$ \\
\hline Model & 424.74 & 9 & 47.19 & 24.01 & 0.0014 \\
$\mathrm{X}_{1}$ & 12.83 & 1 & 12.83 & 6.52 & 0.0510 \\
$\mathrm{X}_{2}$ & 19.22 & 1 & 19.22 & 9.78 & 0.0261 \\
$\mathrm{X}_{3}$ & 26.97 & 1 & 26.97 & 13.72 & 0.0139 \\
$\mathrm{X}_{1} \mathrm{X}_{2}$ & 13.54 & 1 & 13.54 & 6.89 & 0.0468 \\
$\mathrm{X}_{1} \mathrm{X}_{3}$ & 104.14 & 1 & 104.14 & 52.97 & 0.0008 \\
$\mathrm{X}_{2} \mathrm{X}_{3}$ & 29.92 & 1 & 29.92 & 15.22 & 0.0114 \\
$\mathrm{X}_{1}^{2}$ & 5.50 & 1 & 5.50 & 2.80 & 0.1553 \\
$\mathrm{X}_{2}^{2}$ & 0.10 & 1 & 0.10 & 0.053 & 0.8271 \\
$\mathrm{X}_{3}^{2}$ & 215.82 & 1 & 215.82 & 109.78 & 0.0001 \\
Residual & 9.83 & 5 & 1.97 & & \\
Lack of fit & 6.12 & 3 & 2.04 & 1.10 & 0.5090 \\
Pure error & 3.71 & 2 & 1.86 & & \\
Total model & 434.57 & 14 & & & \\
\hline
\end{tabular}

$R^{2}$, determination coefficient; $R_{A d i}^{2}$, adjusted $R^{2} ; \mathrm{CV}$, coefficient of variation.

\subsubsection{Optimization of GL Polysaccharide Extraction}

The response surface methodology was used to investigate the interactions of the variables and determine the optimal level of each variable for the maximal response [31]. The 3D response surface and $2 \mathrm{D}$ contour plots provided graphical representations of the regression equation (Figure 2), providing a means of visualizing the mutual effect of independent variables at different levels on the extraction yield of polysaccharides and the interactions between the independent variables. The 3D response surface plot demonstrated the mutual effect of two variables, with the other variable maintained at the respective zero level. Figure $2 \mathrm{~A}$ depicts the interaction effect of extraction time $\left(\mathrm{X}_{1}\right)$ and extraction temperature $\left(\mathrm{X}_{2}\right)$ on the yield of GL polysaccharides with the ratio of water to raw material $\left(\mathrm{X}_{3}\right)$ fixed at $70 \mathrm{~mL} / \mathrm{g}$. The yield of GL polysaccharides increased slightly with the increasing extraction time and temperature. Furthermore, the contour plot (Figure 2B) showed significant interactions between two variables $(p<0.05$, Table 3 ). The extraction time slightly increased yield of GL polysaccharides, whereas yield increased rapidly with ratio of water to raw material from $60 \mathrm{~mL} / \mathrm{g}$ to $68 \mathrm{~mL} / \mathrm{g}$ (Figure 2C). However, with a further increase of the ratio of water to raw material, the yield decreased. Maximal extraction yield of GL polysaccharides could be achieved with extraction time and ratio of water to raw material $5 \mathrm{~h}$ and $70 \mathrm{~mL} / \mathrm{g}$, respectively. The contour plot (Figure 2D) and the results from Table 3 
$(p<0.05)$ show significant reciprocal interactions between the two variables. The yield of GL polysaccharides increased with increasing ratio of water to raw material and after yield peaked, it decreased slowly (Figure 2E). However, yield increased little with increased extraction temperature when extraction time was set at $5 \mathrm{~h}$. The relationships between the two variables were significant ( $p<0.05$, Table 3, Figure 2F). In conclusion, the highest yield of GL polysaccharides could be obtained with the extraction temperature and ratio of water to raw material of about $100{ }^{\circ} \mathrm{C}$ and $70 \mathrm{~mL} / \mathrm{g}$, respectively.
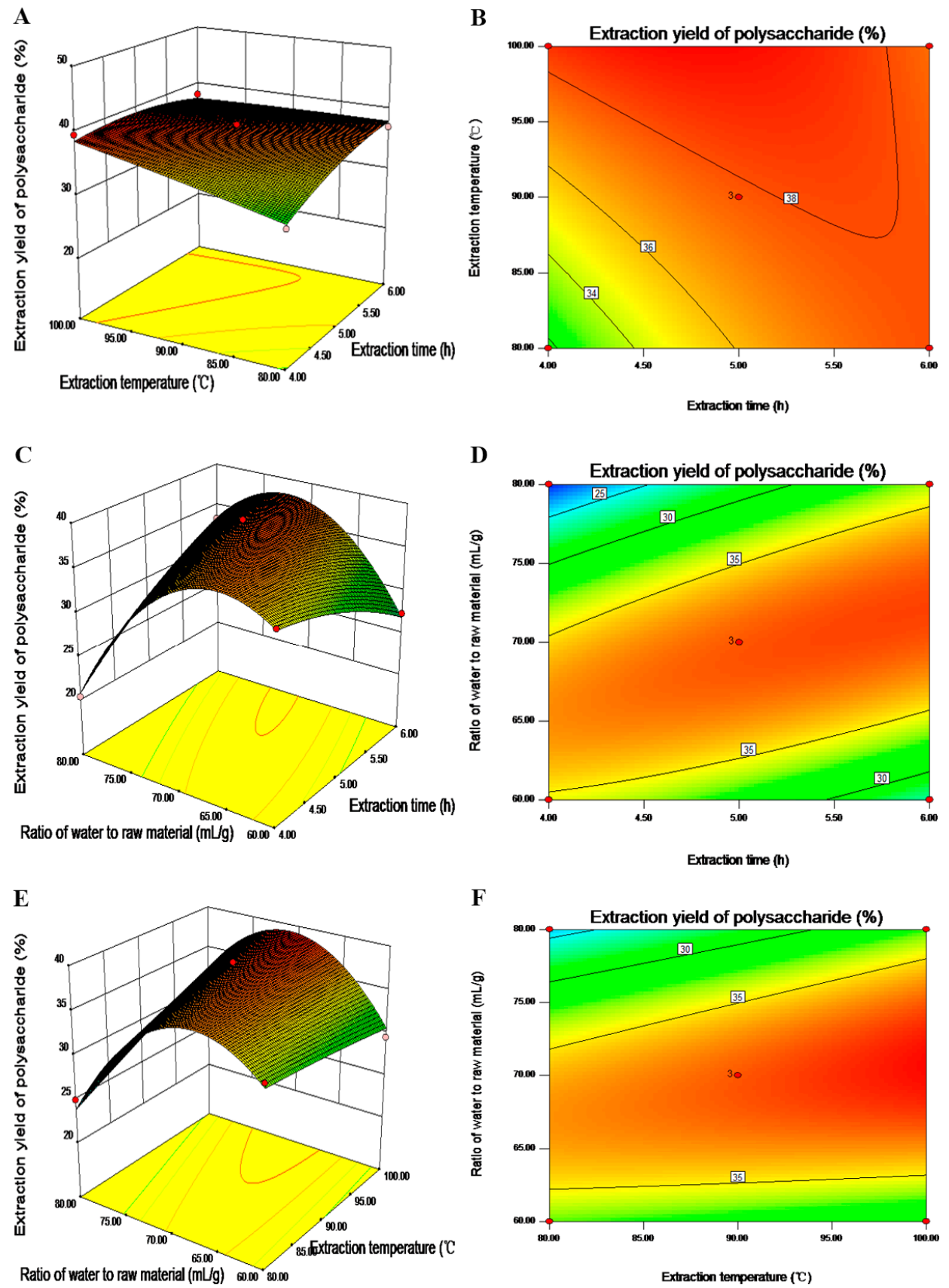

Figure 2. Response surface plots $(\mathbf{A}, \mathbf{C}, \mathbf{E})$ and contour plots $(\mathbf{B}, \mathbf{D}, \mathbf{F})$ showing the interactive effects of extraction time $\left(\mathrm{X}_{1}\right)$, extraction temperature $\left(\mathrm{X}_{2}\right)$ and ratio of water to raw material $\left(\mathrm{X}_{3}\right)$ on yield of GL polysaccharides. 


\subsubsection{Verification of Predictive Model}

According to the Figure 2 and Equation (6), the optimal extraction conditions for GL polysaccharides were as follows: extraction time $\left(\mathrm{X}_{1}\right) 4.63 \mathrm{~h}$, extraction temperature $\left(\mathrm{X}_{2}\right) 100{ }^{\circ} \mathrm{C}$ and ratio of water to raw material $\left(\mathrm{X}_{3}\right) 69.35 \mathrm{~mL} / \mathrm{g}$. Under these optimal extraction conditions, the theoretical maximal extraction yield of GL polysaccharides was predicted to be $39.25 \%$ by the mathematical model. Considering operability in the experiment, the optimal conditions could be adjusted to the following conditions: extraction time $\left(\mathrm{X}_{1}\right) 5 \mathrm{~h}$, extraction temperature $\left(\mathrm{X}_{2}\right) 100^{\circ} \mathrm{C}$ and ratio of water to raw material $\left(\mathrm{X}_{3}\right) 70 \mathrm{~mL} / \mathrm{g}$. To ensure the validation of the model equation, we performed three independent experiments under the modified polysaccharide extraction conditions. The mean polysaccharide extraction was $39.22 \% \pm 0.09 \%$, which agrees well with the predicted value for the good correlation between experimental and predicted values, and the response model is adequate for optimization.

\subsection{Scavenging Activity}

\subsubsection{DPPH Radical Scavenging Activity}

The free radical scavenging activity of GL polysaccharides were measured by DPPH assay. DPPH, a stable $N$-centered free radical, has been often used to analyze the ability of free-radical scavenging properties or hydrogen donation of compounds and medicine materials [32]. As shown in Figure 3, DPPH scavenging by GL polysaccharides increased rapidly with increasing concentrations from $4 \mathrm{mg} / \mathrm{mL}$ to $8 \mathrm{mg} / \mathrm{mL}$, and then grew steadily to peak at $80.71 \%$ with $20 \mathrm{mg} / \mathrm{mL}$ concentration. Therefore, GL polysaccharides, especially at high concentration, had a noticeable scavenging activity on DPPH radicals. Nevertheless, compared to the scavenging rate of the positive standard (VC; ascorbic acid), the antioxidant activity of GL polysaccharides was not as good as VC. The possible mechanism may be their electron donation power to free radicals, thereby terminating the radical chain reaction [33].

\subsubsection{Hydroxyl Radical Scavenging Activity}

The hydroxyl radical is considered the most reactive and poisonous free radical and induces severe damage to adjacent biomolecules as an active initiator for lipids peroxidation [34]. The reaction system containing $\mathrm{Fe}^{2+}-\mathrm{H}_{2} \mathrm{O}_{2}$-salicylic acid in the aqueous phase was used to generate $\mathrm{OH}$ [35] to measure the scavenging activity of GL polysaccharides for hydroxyl radicals (Figure 4). With increasing concentration of GL polysaccharides, the hydroxyl radical scavenging activity increased, and at $20 \mathrm{mg} / \mathrm{mL}$ concentration, its scavenging rate peaked. Furthermore, the antioxidant activity of VC was greater than with GL polysaccharides. Previous studies have suggested that the antioxidant mechanism may be due to the supply of hydrogen by polysaccharides, which combine with radicals and form a stable radical to terminate the radical chain reaction [36]. GL polysaccharides may scavenge hydroxyl radicals by providing hydrogen. However, the exact mechanism relating to the hydroxyl radical scavenging activity by polysaccharides needs further study. 


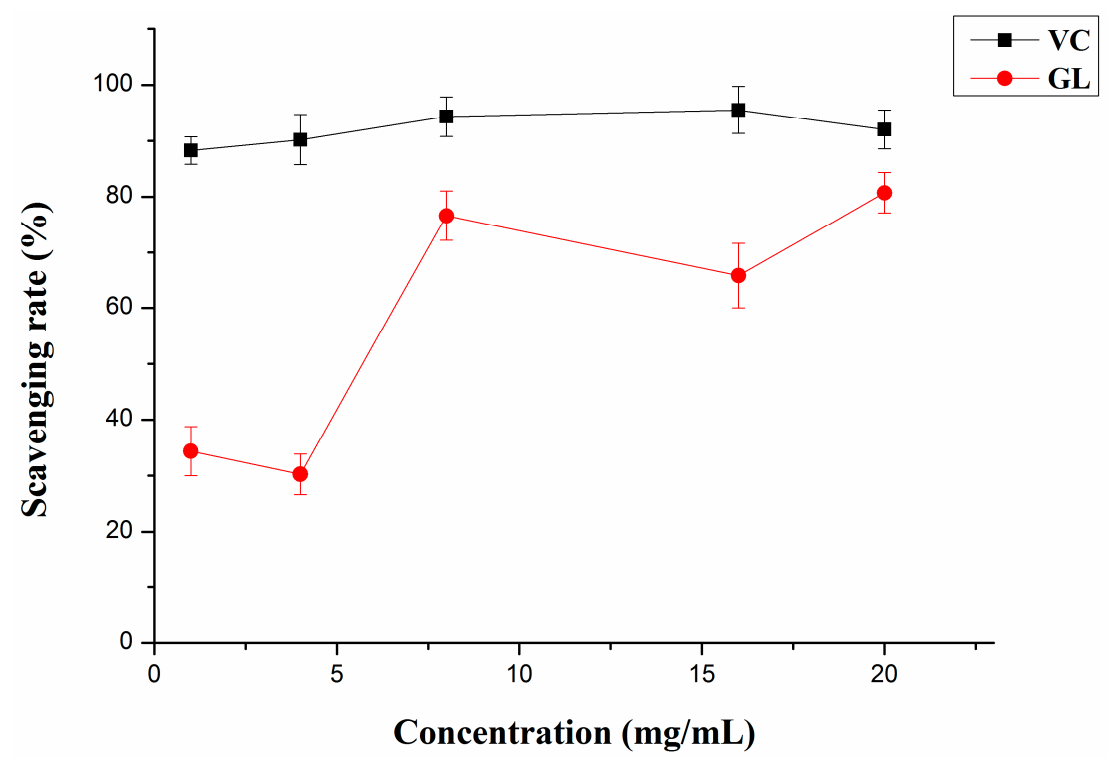

Figure 3. DPPH radical scavenging activity of GL polysaccharides and VC. Data are mean $\pm \mathrm{SD}(n=3)$.

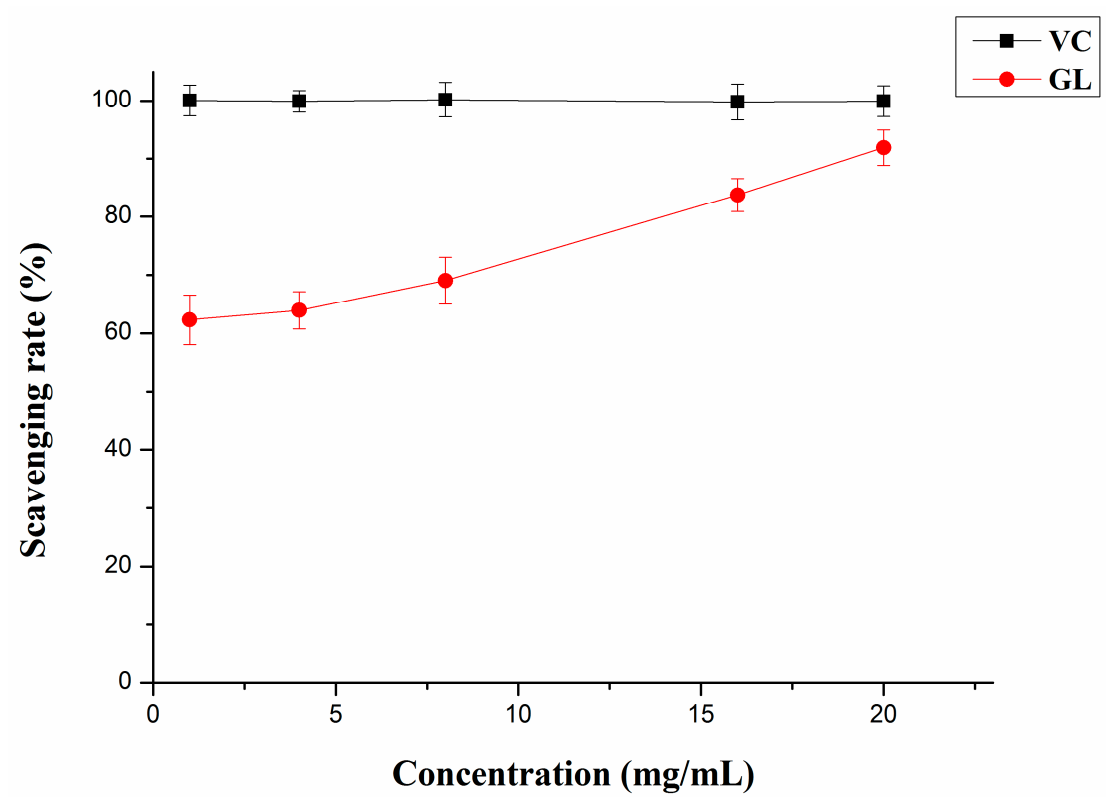

Figure 4. Hydroxyl radical scavenging activity of GL polysaccharides and VC. Data are mean $\pm \operatorname{SD}(n=3)$.

\subsection{Anticancer Activity}

We evaluated the cell inhibition rates of GL polysaccharides on HepG2 cells after incubation at three intervals ( $24 \mathrm{~h}, 48 \mathrm{~h}$, and $72 \mathrm{~h}$ ) via MTT assay. As shown in Figure 5, the growth of HepG2 cells was subject to different inhibition rates at different times with different concentrations of GL polysaccharides, representing the time-effect relationship. With increasing incubation time, the inhibition rate of HepG2 cells increased. The results were significant except for cells incubated between $48 \mathrm{~h}$ and $72 \mathrm{~h}$ at $0.06 \mathrm{mg} / \mathrm{mL}$. Otherwise, the GL polysaccharides inhibited the proliferation of HepG2 cells dose-dependently. However, with $24 \mathrm{~h}$ incubation, cell growth was not inhibited significantly at a low concentration of GL 
polysaccharides, so the polysaccharides had no useful effects until they were at the suitable concentration. As a positive standard, 5-fluorouracil (5-fu) had a greater effect on HepG2 cells than GL polysaccharides did. However, incubation of GL polysaccharides and 5 -fu at low concentrations $(0.06 \mathrm{mg} / \mathrm{mL}$ and $0.6 \mathrm{mg} / \mathrm{mL}$ ) were not significant $(p>0.05)$. Oxidative stress is among the main causes of cancer-related death. If compounds can enhance the level of anti-oxidation and reduce reactive oxygen species content in cancer cells, they may inhibit cell growth [37]. Therefore, the anticancer activity of GL polysaccharides might be ascribed to its effect on scavenging free radicals.

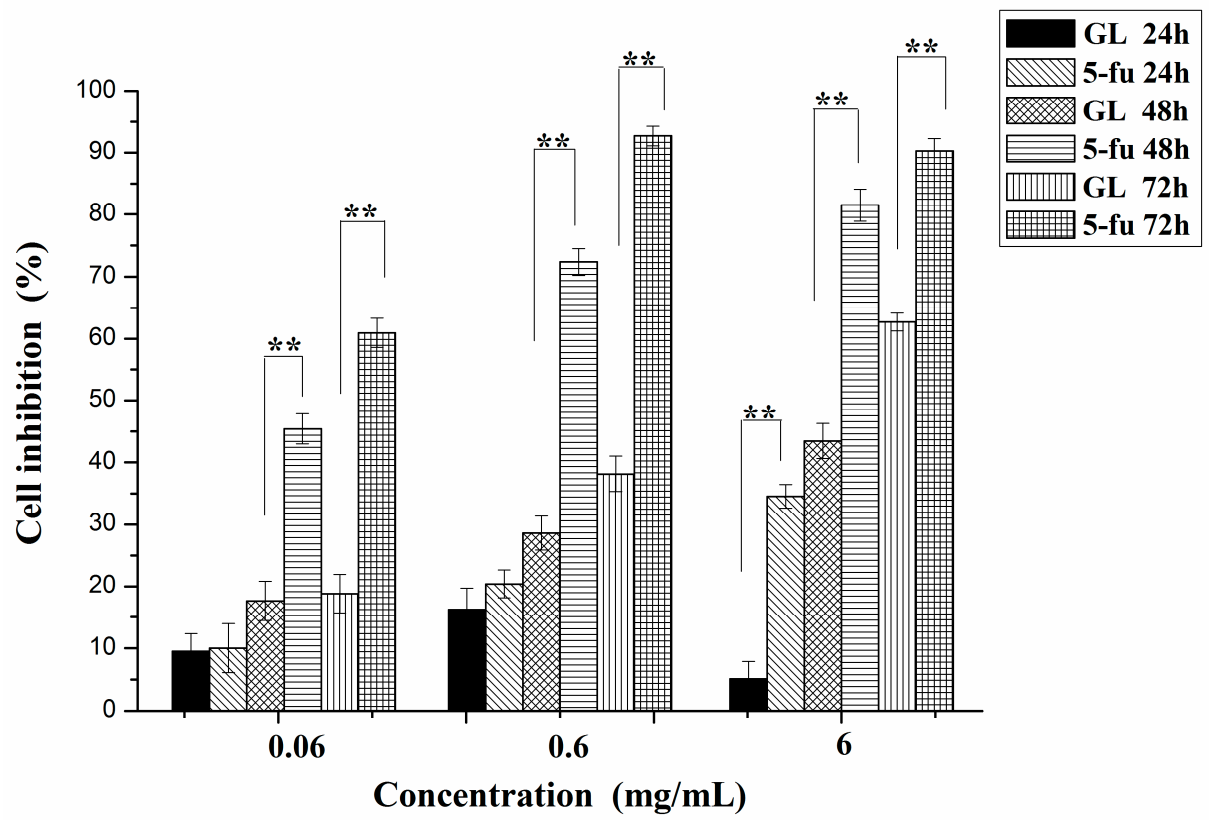

Figure 5. GL polysaccharides and 5-fu were incubated with HepG2 cells for 24, 48, and $72 \mathrm{~h}(n=3)$. ** $p<0.01$.

\section{Experimental Section}

\subsection{Plant and Cell Materials}

Grateloupia livida (Harv.) Yamada (GL) was obtained from Nan Ao Island, Shantou, Guangdong Province, China, and identified by the Nan Ao Marine Biological Research Institute of Shantou University, China. The human liver carcinoma cell line HepG2 was obtained from the Medical College of Shantou University, China.

\subsection{Chemicals and Reagents}

2,2-Diphenyl-1-picrylhydazyl (DPPH), salicylic acid, ascorbic acid (VC), 3-[4,5-dimethylthiazole-2yl]-2,5-diphenyltetrazolium bromide (MTT) and glucose were obtained from Sigma-Aldrich Chemical Co. (St. Louis, MO, USA). Other reagents, including ethanol, dimethyl sulfoxide (DMSO), phenol, concentrated sulfuric acid, hydrogen peroxide $\left(\mathrm{H}_{2} \mathrm{O}_{2}\right)$, and ferrous sulfate $\left(\mathrm{FeSO}_{4}\right)$ were from Shantou Xilong Chemical Factory (Shantou, China). Dulbecco's modified eagle medium (DMEM) was from Thermo Fisher Scientific Inc. (Shanghai, China). Fetal bovine serum was from Biosun Science and Technology (Shanghai, China). 


\subsection{Preparation of $G L$}

GL was washed, smashed, and dried at $60^{\circ} \mathrm{C}$ to prepare the experimental sample. To remove lipid materials and other micromolecule matter thoroughly, GL powders were prepared by operating heating circumfluence with $95 \%$ ethanol, at $90{ }^{\circ} \mathrm{C}$ twice and $3 \mathrm{~h}$ each time. The purified GL powders were then filtrated and dried for use.

\subsection{Polysaccharide Extraction from $G L$}

The prepared GL powders $(0.5 \mathrm{~g})$ were extracted by water in a designed extraction time $(3-7 \mathrm{~h})$, extraction temperature $\left(60-100{ }^{\circ} \mathrm{C}\right)$, and ratio of water to raw material $(50-90 \mathrm{~mL} / \mathrm{g})$ and the extract liquid was concentrated in a rotary evaporator. The solution was precipitated by $80 \%$ ethanol and incubated for $12 \mathrm{~h}$ at $4{ }^{\circ} \mathrm{C}$ in the refrigerator before it was centrifuged at $3500 \mathrm{rpm}$ for $15 \mathrm{~min}$ [38]. Then the precipitant was dissolved in water and frozen at $-80{ }^{\circ} \mathrm{C}$. Crude GL polysaccharides were obtained by lyophilization. The content of GL polysaccharides was measured by the common phenol-sulfuric acid method, with D-glucose used as the standard to construct a standard curve. The percentage polysaccharide yield (\%) was calculated as follows [39]:

$$
\text { GL polysaccharides extraction yield }(\%)=\frac{\mathrm{X} \times \mathrm{V}}{\mathrm{W} \times 10^{3}}
$$

where $\mathrm{X}(\mathrm{mg} / \mathrm{mL})$ is the concentration of GL polysaccharide solution, V $(\mathrm{mL})$ is the volume of GL polysaccharide solution and $\mathrm{W}(\mathrm{g})$ is the dried powder of GL weight.

\subsection{Single Factor Experimental Design}

Single factor experiments were performed to investigate the effect of extraction time, extraction temperature, and ratio of water to raw material on GL polysaccharide extraction yield. During the optimization of experimental factors, one factor was changed and the other factors were kept constant in each experiment. All experiments were repeated three times.

\subsection{BBD and Statistical Analysis}

From the preliminary single factor experiment design, BBD was performed for further optimization of GL polysaccharide extraction. Three parameters, including extraction time, extraction temperature, and ratio of water to raw material, were designated $\mathrm{X}_{1}, \mathrm{X}_{2}$, and $\mathrm{X}_{3}$, respectively (Table 1). Each of the independent variables had coded levels of -1 (low), 0 (central), +1 (high). The quadratic polynomial equation reflecting the relationship between three independent variables and the response variable (extraction yield of GL polysaccharides) is as follows [40]:

$$
\mathrm{Y}=\beta_{0}+\sum_{i=1}^{3} \beta_{\mathrm{i}} \mathrm{X}_{i}+\sum_{i=1}^{3} \beta_{i i} \mathrm{X}_{i}^{2}+\sum_{i=1}^{2} \sum_{j=i+1}^{3} \beta_{i j} \mathrm{X}_{i} \mathrm{X}_{j}
$$

where $\mathrm{Y}$ is the response variable; $\beta_{0}, \beta_{i}, \beta_{i i}$, and $\beta_{i j}$ are regression coefficients of variables for intercept, linearity, quadratic, and interaction terms, respectively; and $\mathrm{X}_{i}$ and $\mathrm{X}_{j}$ are the coded independent variables $(i \neq j)$. In the whole design, 15 experimental runs were performed in random order, with 12 factorial runs 
and three center runs. The factorial point is the $3 \mathrm{D}$ vertex consisting of independent variables $\left(\mathrm{X}_{1}, \mathrm{X}_{2}\right.$ and $\mathrm{X}_{3}$ ). Three experiments were performed at the center point $(0)$ to evaluate the pure error [41]. The design of the experiments is in Table 2. All trials were performed in triplicate. Statistical analysis of data was performed to establish the mathematical model by the BBD method, evaluating the effects of each independent variable on the response.

\subsection{Antioxidant Activity Assay in Vitro}

\subsubsection{DPPH Radical Scavenging Activity}

The DPPH radical scavenging activity assay was performed as described [42], with a few modifications. Briefly, $250 \mu \mathrm{L}$ of $0.1 \mathrm{mM}$ freshly prepared DPPH solution (in $95 \%$ ethanol) was added to $50 \mu \mathrm{L} \mathrm{GL}$ polysaccharide solution at $1 \mathrm{mg} / \mathrm{mL}, 4 \mathrm{mg} / \mathrm{mL}, 8 \mathrm{mg} / \mathrm{mL}, 16 \mathrm{mg} / \mathrm{mL}$ and $20 \mathrm{mg} / \mathrm{mL}$, respectively. The mixture was shaken vigorously and incubated at $25{ }^{\circ} \mathrm{C}$ for $30 \mathrm{~min}$ in the dark, before measuring the absorbance at $517 \mathrm{~nm}$. VC (ascorbic acid) was used as the positive standard. The GL polysaccharide ability to scavenge DPPH was calculated by the following equation:

$$
\text { Scavenging rate }(\%)=\frac{1-\left(\mathrm{A}_{\mathrm{i}}-\mathrm{A}_{\mathrm{j}}\right)}{\mathrm{A}_{0}} \times 100 \%
$$

where $A_{i}$ is the absorbance obtained from GL polysaccharides mixed with DPPH solution, $A_{j}$ is the absorbance of GL polysaccharides with $95 \%$ ethanol and $A_{0}$ is the absorbance of DPPH solution with $95 \%$ ethanol. Data are expressed as mean \pm SD of three independent experiments.

\subsubsection{Hydroxyl Radical Scavenging Assay}

The hydroxyl radical scavenging ability of GL polysaccharides was analyzed by the hydroxyl radical system generated by the Fenton reaction [43] with minor changes. In brief, GL polysaccharides were dissolved in distilled water at $1 \mathrm{mg} / \mathrm{mL}, 4 \mathrm{mg} / \mathrm{mL}, 8 \mathrm{mg} / \mathrm{mL}, 16 \mathrm{mg} / \mathrm{mL}$ and $20 \mathrm{mg} / \mathrm{mL}$. The reaction mixture contained $50 \mu \mathrm{L} \mathrm{FeSO}_{4}(6 \mathrm{mM}), 50 \mu \mathrm{L} \mathrm{H}_{2} \mathrm{O}_{2}(6 \mathrm{mM})$ and $100 \mu \mathrm{L}$ GL polysaccharides of varying concentrations. After shaking and incubation at room temperature for $10 \mathrm{~min}, 50 \mu \mathrm{L}$ salicylic acid was added to the mixture, then shaken and incubated at room temperature for another $30 \mathrm{~min}$, and the absorbance of the mixture was measured at $510 \mathrm{~nm}$. VC was considered the positive standard. The hydroxyl radical scavenging rate was calculated by the following equation:

$$
\text { Scavenging rate }(\%)=\frac{1-\left(\mathrm{A}_{\mathrm{i}}-\mathrm{A}_{\mathrm{j}}\right)}{\mathrm{A}_{0}} \times 100 \%
$$

where $\mathrm{A}_{\mathrm{i}}$ is the absorbance obtained from the reaction mixture $\left(\mathrm{FeSO}_{4}\right.$ and $\left.\mathrm{H}_{2} \mathrm{O}_{2}\right)$ with GL polysaccharides and salicylic acid, $\mathrm{A}_{\mathrm{j}}$ is the absorbance of the reaction mixture with GL polysaccharides and $\mathrm{A}_{0}$ is the absorbance of reaction mixture with salicylic acid. Data are expressed as mean \pm SD of three independent experiments. 


\subsection{Cell Cytotoxicity Assay in Vitro}

\subsubsection{Cell Culture}

DMEM medium was supplemented with $10 \%$ fetal bovine serum, penicillin (100 units $/ \mathrm{mL})$ and streptomycin (100 units $/ \mathrm{mL})$. HepG2 Cells were cultured in DMEM medium and incubated at $37^{\circ} \mathrm{C}$ in a humidified $5 \% \mathrm{CO}_{2}$ incubator.

\subsubsection{MTT Assay}

The cytotoxic effect of GL polysaccharides on HepG2 cells was evaluated by the standard MTT assay. HepG2 cells were seeded at $5 \times 10^{4}$ per well in 96-well microplates and incubated for $24 \mathrm{~h}$ to allow cell attachment. Then different concentrations of GL polysaccharides dissolved $(0.06 \mathrm{mg} / \mathrm{mL}, 0.6 \mathrm{mg} / \mathrm{mL}$, $6 \mathrm{mg} / \mathrm{mL}$ ) in DMEM were added to each well in the plates. 5-fluorouracil (5-fu) was considered the positive standard. The cells cultured with DMEM medium were the control. The plates were incubated in a humidified $5 \% \mathrm{CO}_{2}$ incubator at $37^{\circ} \mathrm{C}$ for $24 \mathrm{~h}, 48 \mathrm{~h}$, and $72 \mathrm{~h}$, respectively. Then, $20 \mu \mathrm{L}(5 \mathrm{mg} / \mathrm{mL})$ MTT solution was added to the medium and further incubated for $4 \mathrm{~h}$ in the dark. The medium in each well was removed and $150 \mu \mathrm{L}$ DMSO was added to dissolve the purple formazan crystals. The absorbance at $490 \mathrm{~nm}$ (A490) was read on microplate reader and the cell cytotoxicity rate was calculated as follows:

$$
\text { Cell cytotoxicity rate }(\%)=\frac{1-\mathrm{A}_{\mathrm{i}}}{\mathrm{A}_{\mathrm{j}}} \times 100 \%
$$

where $A_{i}$ is the absorbance from the treatment group and $A_{j}$ is the absorbance of the control group. Data are expressed as mean \pm SD from three independent experiments.

\section{Conclusions}

In summary, the polysaccharides from G. livida were extracted by the heating circumfluence method and the extraction process was successfully optimized by the BBD method. From the single-factor experiments, the optimization of the extraction conditions, including extraction time, extraction temperature and ratio of water to material, were determined as extraction time $5 \mathrm{~h}$, extraction temperature $100{ }^{\circ} \mathrm{C}$ and ratio of water to raw material $70 \mathrm{~mL} / \mathrm{g}$. Under these conditions, the experimental yield of polysaccharides was $39.22 \% \pm 0.09 \%$, close to the predicted yield of $39.25 \%$. Hence, the model established by BBD was adequate for GL polysaccharide extraction. The antioxidant and anticancer activities of GL polysaccharides were evaluated. GL polysaccharides possessed certain inhibitory effects on DPPH radical and hydroxyl radicals. For anticancer activity, GL polysaccharides can suppress HepG2 cell proliferation somewhat, but are not as good as 5-fu. The results obtained in this experiment should be useful for the further exploitation of the seaweed.

\section{Acknowledgments}

This work was supported by Guangdong Provincial Natural Science Foundation (NO. 2015A030313432). We appreciate the help from Marine Biological Research Institute, Shantou University, for collecting Grateloupia livida (Harv.) Yamada. 


\section{Author Contributions}

Danyan Ye, Zebin Jiang, Fuchun Zheng, Yicun Chen and Ganggang Shi designed the experiment. Danyan Ye and Zebin Jiang performed the experiments. Danyan Ye, Zebin Jiang, Peihong Chen, Hongmei Wang and Yicun Chen analyzed the data. Danyan Ye and Yicun Chen wrote the paper. Fuchun Zheng, Yanmei Zhang, Fenfei Gao, Yicun Chen, Hongmei Wang and Ganggang Shi revised the paper. All authors discussed the results and approved the final manuscript.

\section{Conflicts of Interest}

The authors declare no conflict of interest.

\section{References}

1. Wilkes, R.J.; Morabito, M.; Gargiulo, G.M. Taxonomic considerations of a foliose Grateloupia species from the Straits of Messia. J. Appl. Phycol. 2006, 18, 663-669.

2. Fang, Y.C.; Wang, Y.; Luo, Y. Investigation of medicinal red algae resources and proposals for its development and utilization. Chin. J. Mar. Drugs 2010, 29, 63-67.

3. Zhang, C.; Yang, F.; Zhang, X.W. Grateloupia longifolia polysaccharide inhibits angiogenesis by down regulating tissue factor expression in HMEC-1 endothelial cells. Br. J. Pharmacol. 2006, 148, 741-751.

4. Liu, F.; Pang, S.J. stress tolerance and antioxidant enzymatic activities in the metabolisms of the reactive oxygen species in two intertidal red algae Grateloupia turuturu and Palmaria palmate. J. Exp. Mar. Biol. Ecol. 2010, 382, 82-87.

5. Emma, A.H.; Ruth, F.; Susan, M.C. Virucidal activity of polysaccharide extracts from four algal species against herpes simplex virus. Antivir. Res. 2009, 83, 282-289.

6. Ngo, D.H.; Kim, S.K. Sulfated polysaccharides as bioactive agents from marine algae. Int. J. Biol. Macromol. 2013, 62, 70-75.

7. Noda, H.; Amano, H.; Arashima, K. Antitumor activity of marine algae. Hydrobiologia 1990, 204, $577-584$.

8. Jiang, Z.B.; Chen, Y.C. Antioxidant, antibacterial and antischistosomal activities of extracts from Grateloupia livida (Harv). Yamada. PLoS ONE 2013, 8, e80413.

9. Ma, R.J.; Guo, S.J.; Yang, Y.L. Research process of development and function of Rhodophyta in east area of Guangdong. Food Sci. 2007, 28, 580-583.

10. Fenoradosoa, T.A.; Delattre, C.; Laroche, C.; Wadouachi, A.; Dulong, V.; Picton, L.; Andriamadio, P.; Michaud, P. Highly sulphated galactan from Halymenia durvillei (Halymeniales, Rhodophyta), a red seaweed of Madagascar marine coasts. Int. J. Biol. Macromol. 2009, 45, 140-145.

11. Delattre, C.; Fenoradosoa, T.A.; Michaud, P. Galactans: An overview of their most important sourcing and applications as natural polysaccharides. Braz. Arch. Biol. Technol. 2011, 54, 1075-1092.

12. Chu, H.L.; Mao, H.; Feng, W. Effects of sulfated polysaccharides from Masson pine (Pinus massoniana) pollen on the proliferation and cell cycle of HepG2 cells. Int. J. Biol. Macromol. 2003, 55, 104-108. 
13. Wang, W. Research in Separation and Structure of Sulfated Polysaccharides from Three Kinds of Grateloupia. Master's Thesis, Ocean University of China, Qingdao, China, 2012.

14. Shanab, S.M.M. Antioxidant and antibiotic activities of some seaweeds (Egyptian isolates). Int. J. Agric. Biol. 2007, 9, 220-225.

15. Vijayabaskar, P.; Vaseela, N.; Thirumaran, G. Potential antibacterial and antioxidant properties of a sulfated polysaccharide from the brown marine algae Sargassum swartzii. Chin. J. Nat. Med. 2012, 10, 421-428.

16. Yang, D.J.; Yang, Y.L.; Wang, Z.H.; Guo, S.J.; Liu, L.M.; Zhong, W.H.; Rao, P.Y. Extraction and properties of polysaccharides from Grateloupia filicna. Food Sci. Technol. 2006, 36, 162-164.

17. Zhang, Z.Y. Antitumor effect of Grateloupia filicna on U87 cell and its xenografts in nude mice. J. Chongqing Med. Univ. 2011, 36, 1051-1053.

18. Jin, M.L.; Zhao, K.; Huang, Q.S. Isolation, structure and bioactivities of the polysaccharides from Angelica sinensis (Oliv.) Diels: A review. Carbohydr. Polym. 2012, 89, 713-722.

19. Zhu, Y.M.; Wang, Y.F.; Zhang, M.Y. The study on the extraction and the antivirus activity of amylose extracted from Grateloupia filicina. J. Chin. Med. Mat. 2006, 29, 256-259.

20. Fan, T.; Hu, J.G.; Fu, L.D. Optimization of enzymolysis-ultrasonic assisted extraction of polysaccharides from Momordica charabtia L. by response surface methodology. Carbohydr. Polym. 2015, 115, 701-706.

21. Kurd, F.; Samavati, V. Water soluble polysaccharides from Spirulina platensis: Extraction and in vitro anti-cancer activity. Int. J. Biol. Macromol. 2015, 74, 498-506.

22. Wang, Y.P.; Yi, L.; Hu, Y.H. Optimization of polysaccharides extraction from Trametes robiniophila and its antioxidant activities. Carbohydr. Polym. 2014, 111, 324-332.

23. Samavati, A.; Manoochehrizade, A. Polysaccharide extraction from Malva sylvestris and its anti-oxidant activity. Int. J. Biol. Macromol. 2013, 60, 427-436.

24. Zhu, C.P.; Zhai, X.C.; Li, L.Q.; Wu, X.X.; Bing, L. Response surface optimization of ultrasound-assisted polysaccharides extraction from pomegranate peel. Food Chem. 2015, 177, 139-146.

25. Zou, Y.F.; Chen, X.F.; Yang, W.Y.; Liu, S. Response surface methodology for optimization of the ultrasonic extraction of polysaccharides from Codonopsis pilosula Nannf. var. modesta. L.T. Shen. Carbohydr. Polym. 2011, 84, 503-508.

26. Hou, X.J.; Chen, W. Optimization of extraction process of crude polysaccharides from wild edible BaChu mushroom by response surface methodology. Carbohydr. Polym. 2008, 72, 67-74.

27. Murthy, M.S.R.C.; Swaminathan, T.; Rakshit, S.K.; Kosugi, Y. Statistical optimization of lipase catalyzed hydrolysis of methyloleate by response surface methodology. Bioprocess. Eng. 2000, 22, $35-39$.

28. Zhao, S.; Rong, C.B.; Liu, Y.; Xu, F.; Wang, S.X.; Duan, C.L.; Chen, J.C.; Wu, X.Y. Extraction of a soluble polysaccharide from Auricularia polytricha and evaluation of its anti-hypercholesterolemic effect in rats. Carbohydr. Polym. 2015, 122, 39-45.

29. Bahaabad, G.A.; Gharibzahedi, S.M.T.; Esmaiili, M.; Alizadeh, M. Response Surface modeling for optimization of textural and color Characteristics of dried grapes. Int. J. Food. Eng. 2014, 10, 493-502.

30. Mason, R.L.; Gunst, R.F.; Hess, J.L. Statistical Design and Analysis of Experiments-English with Applications to Engineering and Science, 2nd ed.; John Wiley \& Sons: New York, NY, USA, 2003; Volume 33, pp. 105-106. 
31. Balavigneswaran, C.K.; Kumar, T.S.J.; Packiaraj, R.M.; Veeraraj, A.; Prakash, S. Anti-oxidant activity of polysaccharides extracted from Isocrysis galbana using RSM optimized conditions. Int. J. Biol. Macromol. 2013, 60, 100-108.

32. Hatano, T.; Edamatsu, R.; Hiramatsu, M.; Mori, A.; Fujita, Y.; Yasuhara, T.; Yoshida, T; Okuda, T. Effects of the interaction of tannins with co-existing substances, VI: Effects of tannins and related polyphenols on superoxide anion radical, and on 1,1-diphenyl-2-picrylhydrazyl radical. Chem. Pharm. Bull. 1989, 37, 2016-2021.

33. Lai, F.R.; Wen, Q.B.; Li, L.; Wu, H.; Li, X.F. Antioxidant activities of water-soluble polysaccharide extracted from mung bean (Vigna radiate L.) hull with ultrasonic assisted treatment. Carbohydr. Polym. 2010, 81, 323-329.

34. Chance. B.; Sies, H.; Boveris, A. Hydroperoxide metabolism in mammalian organs. Physiol. Rev. 1979, 59, 527-605.

35. Jiang, P.; Yuan, L.; Cai, D.L.; Jiao, L.L.; Zhang, L.P. Characterization and antioxidant activities of the polysaccharides from mycelium of Phellinus pini and culture medium. Carbohydr. Polym. 2015, 117, 600-604.

36. Chen, R.Z.; Liu, Z.Q.; Zhao, J.M.; Chen, R.P.; Meng, F.L.; Zhang, M.; Ge, W.C. Antioxidant and immunobiological activity of water-soluble polysaccharide fractions purified from Acanthopanax senticosu. Food Chem. 2011, 127, 434-440.

37. Zhang, T.T.; Lu, C.L.; Jiang, J.G.; Wang, M.; Wang, D.M.; Zhu, W. Bioactivities and extraction optimization of crude polysaccharides from the fruits and leaves of Rubus chingii Hu. Carbohydr. Polym. 2015, 130, 307-315.

38. Cui, H.H.; Zhao, Y.R.; Wang, S.M. Astragalus polysaccharide enrichment process. LiShiZhen Med. Med. Res. 2003, 24, 2075-2078.

39. Ghavi, P.P. The extraction process optimization of antioxidant polysaccharides from Marshmallow (Althaea officinalis L.) roots. Int. J. Biol. Macromol. 2015, 75, 51-57.

40. Liu, Z.G.; Dang, J.; Wang, Q.L.; Yu, M.F.; Jiang, L.; Mei, L.J.; Shao, Y.; Tao, Y.D. Optimization of polysaccharides from Lycium ruthenicum fruit using RSM and its anti-oxidant activity. Int. J. Biol. Macromol. 2013, 61, 127-134.

41. Cai, W.R. Optimization of extraction technology of soluble polysaccharides in Opuntia milpa alta by response surface methodology. J. Anhui Agric. Sci. 2007, 35, 6819-6822.

42. Zhang, Q.B.; Yu, P.Z.; Li, Z.E.; Zhang, H.; Xu, Z.H.; Li, P.C. Antioxidant activities of sulfated polysaccharide fractions from Porphyra haitanesis. J. Appl. Phycol. 2003, 15, 305-310.

43. Heo, S.J.; Park, E.J.; Lee, K.W.; Jeon, Y.J. Antioxidant activities of enzymatic extracts from brown seaweeds. Bioresour. Technol. 2005, 96, 1613-1623.

Sample Availability: Samples of polysaccharides from Grateloupia livida (Harv.) Yamada are available from the authors.

(C) 2015 by the authors; licensee MDPI, Basel, Switzerland. This article is an open access article distributed under the terms and conditions of the Creative Commons Attribution license (http://creativecommons.org/licenses/by/4.0/). 